\title{
Bilateral internal thoracic artery grafting improves long-term survival in patients with reduced ejection fraction: A propensity-matched study with 30-year follow-up
}

\author{
David L. Galbut, MD, ${ }^{a}$ Paul A. Kurlansky, MD, ${ }^{b}$ Ernest A. Traad, MD, ${ }^{b}$ Malcolm J. Dorman, MD, \\ Melinda Zucker, MSRN, ${ }^{\mathrm{c}}$ and George Ebra, EdD ${ }^{\mathrm{a}, \mathrm{c}}$
}

\begin{abstract}
Objective: Bilateral internal thoracic artery (BITA) grafting has been shown to improve long-term survival after coronary artery bypass grafting. However, there has been reluctance to use this technique in higher-risk patients. Patients with reduced ejection fraction (EF) have been shown to present a higher operative risk and reduced long-term survival. We studied the perioperative and long-term results of BITA versus single internal thoracic artery grafting (SITA) in a large population of patients with reduced EF in whom BITA grafting was broadly applied.
\end{abstract}

\begin{abstract}
Methods: Between February 1972 and May 1994, 4537 consecutive patients in whom EF was recorded underwent SITA (2340) or BITA (2197) grafting. Prospectively collected clinical data recorded EF categorically as less than 0.30 (group I; $\mathrm{n}=233$ ), 0.30 to 0.50 (group II; $\mathrm{n}=1256$ ), or greater than 0.50 (group III; $\mathrm{n}=3048$ ). Multivariable analyses were performed to determine correlates of operative and late mortality. Optimal matching using propensity scoring was used to create matched SITA and BITA cohorts: group I, SITA and BITA, $\mathrm{n}=87$ each; group II, SITA and BITA, $\mathrm{n}=448$ each; group III, SITA and BITA, $\mathrm{n}=1137$ each. Equality of survival distribution was tested by the log-rank algorithm.
\end{abstract}

Results: There was no difference in operative mortality between matched SITA and BITA groups (group I: SITA vs BITA, $10.3 \%$ vs $6.9 \%, P=.418$; group II: $4.7 \%$ vs $4.5 \%, P=.873$; group III: $3.2 \%$ vs $2.0 \%, P=.086$ ). SITA versus BITA was not a predictor of operative mortality on logistic regression analysis. There was no difference in freedom from any postoperative complication, including sternal wound infection, between matched SITA and BITA groups. Late survival was significantly enhanced with the use of BITA grafting in groups II and III (10- and 20-year survival, SITA vs BITA, in group II: $57.7 \% \pm 0.3 \%$ and $19 \% \pm 2.5 \%$ vs $62.0 \% \pm 2.3 \%$ and $33.1 \% \pm 3.4 \%$, respectively, $P=.016$; and in group III: $67.1 \% \pm 1.4 \%$ and $35.8 \% \pm 1.7 \%$ vs $74.6 \% \pm$ $1.3 \%$ and $38.1 \% \pm 2.1 \%$, respectively, $P=.012$ ). Likewise, choice of SITA versus BITA was a significant predictor of late mortality on Cox regression in both groups II $(P<.007)$ and III $(P<.001)$.

Conclusions: Broadly applied BITA compared with SITA grafting in propensity-matched patients provides enhanced long-term survival with no increase in operative mortality or morbidity for patients with normal and reduced EF. The expanded use of BITA grafting should be seriously considered. (J Thorac Cardiovasc Surg 2012;143:844-53)

Supplemental material is available online.

\footnotetext{
From the Aventura Medical Center, ${ }^{a}$ Aventura, Fla; Florida Heart Research Institute, Miami, Fla; and JFK Medical Center, ${ }^{\mathrm{c}}$ Atlantis, Fla.

This study was supported by an unrestricted grant from the Florida Heart Research Institute, Miami, Fla.

Disclosures: Authors have nothing to disclose with regard to commercial support.

Read at the 37th Annual Meeting of the Western Thoracic Surgical Association, Colorado Springs, Colorado, June 22-25, 2011.

Received for publication June 7, 2011; revisions received Nov 17, 2011; accepted for publication Dec 14, 2011; available ahead of print Jan 16, 2012.

Address for reprints: David L. Galbut, MD, 4770 Biscayne Boulevard, Suite 860, Miami, FL 33137 (E-mail: david@dgalbutmd.com).

$0022-5223 / \$ 36.00$

Copyright (c) 2012 by The American Association for Thoracic Surgery

doi:10.1016/j.jtcvs.2011.12.026
}

Twenty-five years ago, we reported a 12-year experience with 227 patients who underwent bilateral internal thoracic artery (BITA) grafting with low operative risk and excellent intermediate-term results. ${ }^{1}$ Several subsequent retrospective studies have documented an advantage for BITA over single internal thoracic artery (SITA) grafting in reducing late mortality and cardiac events. ${ }^{2-6}$

Patients with reduced ejection fraction (EF) undergoing coronary artery bypass grafting (CABG) have an increased operative mortality $(\mathrm{OM})^{7-12}$ and reduced late survival ${ }^{10,11,13-16}$ compared with patients with normal EF. Because of the reluctance to use BITA grafting in patients with increased risk, the impact of this surgical approach on perioperative and long-term survival in this high-risk group remains undefined. To determine the influence of BITA grafting in patients with left ventricular dysfunction, we report the clinical outcomes with a 30-year follow-up 

Abbreviations and Acronyms
BITA = bilateral internal thoracic artery
$\mathrm{CABG}=$ coronary artery bypass grafting
$\mathrm{EF}=$ ejection fraction
ITA = internal thoracic artery
LAD $=$ left anterior descending
LITA $=$ left internal thoracic artery
$\mathrm{OM}=$ operative mortality
RITA = right internal thoracic artery
SITA $=$ single internal thoracic artery

from a consecutive cohort of patients in whom one third had impaired systolic function and approximately one half received BITA grafting.

\section{MATERIALS AND METHODS}

This report involves 4537 consecutive patients who underwent CABG between February 1972 and May 1994, 2340 of whom received SITA grafting and 2197 received BITA grafting. Waiver of informed consent was granted by the institutional review board. The study population consisted of 146 patients receiving SITA and 87 patients receiving BITA with an EF less than 0.30 (group I); 656 patients receiving SITA and 600 patients receiving BITA with an EF between 0.30 and 0.50 (group II); and 1538 patients receiving SITA and 1510 patients receiving BITA with an EF greater than 0.50 (group III). Appendix E1 shows a listing of clinical variables associated with unmatched patients. Excluded from this study were patients with concomitant cardiovascular procedures and those in whom only 1 distal graft was performed. The series includes all elective, urgent, emergency, and salvage cases.

To adjust for differences in patient risk factors, patients receiving SITA and BITA in groups I, II, and III were matched by propensity score as described in the "Statistical Analysis" section. Groups I, II, and III matched patients constitute the clinical material for this comparative analysis. The coronary and perioperative risk factors for propensity-matched patients are summarized in Table 1. Although patients receiving SITA and BITA had different risk profiles before matching, there were no significant differences in any of the risk factors in propensity-matched groups I, II, or III.

Patient preoperative anginal symptoms were defined by the Canadian Cardiovascular Society. Patients with unstable angina included patients with Canadian Cardiovascular Society class III or IV. In group I SITA, there were 4 patients $(4.6 \%)$ in class I, 1 patient $(1.1 \%)$ in class II, 27 patients $(31.0 \%)$ in class III, and 55 patients $(63.2 \%)$ in class IV. In group I BITA, there were 7 patients $(8.0 \%)$ in class I, 3 patients $(3.4 \%)$ in class II, 31 patients $(35.6 \%)$ in class III, and 46 patients $(52.9 \%)$ in class IV. The distribution of class III or IV symptoms was comparable for patients receiving SITA and BITA $(94.2 \%$ vs $88.5 \% ; P=.280)$.

In group II SITA, there were 9 patients $(2.0 \%)$ in class I, 18 patients $(4.0 \%)$ in class II, 191 patients $(42.6 \%)$ in class III, and 230 patients $(51.3 \%)$ in class IV. In group II BITA, there were 16 patients $(3.6 \%)$ in class I, 23 patients $(5.1 \%)$ in class II, 199 patients $(46.9 \%)$ in class III, and 199 patients $(44.4 \%)$ in class IV. There was no significant difference in the proportion of group II patients receiving SITA $(93.9 \%)$ and BITA $(91.3 \%)$ who had class III or IV symptoms $(P=.127)$.

In group III SITA, there were 29 patients $(2.6 \%)$ in class I, 62 patients $(5.5 \%)$ in class II, 579 patients $(50.9 \%)$ in class III, and 467 patients $(41.1 \%)$ in class IV. In group III BITA, there were 38 patients $(3.3 \%)$ in class I, 69 patients $(6.1 \%)$ in class II, 542 patients $(47.7 \%)$ in class III, and 488 patients $(42.9 \%)$ in class IV. The distribution of class III or IV symptoms is similar for SITA and BITA in group III (92.0\% vs $90.6 \%$; $P=.234)$.

\section{Operative Data}

The operation was performed in group I SITA electively in 27 cases $(31.0 \%)$, urgently in 47 cases $(54.0 \%)$, on an emergency basis in 10 cases $(11.5 \%)$, and on a salvage basis in 3 cases $(3.4 \%)$. In group I BITA, the operation was performed electively in 30 cases $(34.5 \%)$, urgently in 53 cases $(60.9 \%)$, on an emergency basis in 3 cases $(3.4 \%)$, and on a salvage basis in 1 case $(1.1 \%)$. A comparison of elective versus non-elective urgency revealed no significant difference $(P=.630)$. Operations in 10 SITA $(11.5 \%)$ and 9 BITA $(10.3 \%)$ cases were repeat operations $(P=.808)$.

In group II SITA, the operation was performed electively in 190 cases $(42.4 \%)$, urgently in 217 cases $(48.4 \%)$, on an emergency basis in 36 cases $(8.0 \%)$, and on a salvage basis in 5 cases $(1.1 \%)$. In group II BITA, the operation was performed electively in 201 cases $(44.9 \%)$, urgently in 229 cases $(51.1 \%)$, on an emergency basis in 18 cases $(4.0 \%)$, and on a salvage basis in 0 cases $(0.0 \%)$. The distribution of non-elective cases was similar for the 2 cohorts $(57.6 \%$ vs $55.1 \% ; P=.459)$.

In group III SITA, the operation was performed electively in 561 cases $(49.3 \%)$, urgently in 477 cases $(42.0 \%)$, on an emergency basis in 94 cases $(8.3 \%)$, and on a salvage basis in 5 cases $(0.4 \%)$. In group III BITA, the operation was performed electively in 565 cases $(49.7 \%)$, urgently in 533 cases $(46.9 \%)$, on an emergency basis in 38 cases $(3.3 \%)$, and on a salvage basis in 1 case $(0.1 \%)$. The distribution of nonelective cases was similar for the 2 cohorts $(50.7 \%$ vs $50.3 \% ; P=.867)$. Operations in 77 patients receiving SITA $(6.8 \%)$ and 82 patients receiving BITA $(7.2 \%)$ were repeats $(P=.681)$.

Details of the operative technique used in the present series, including internal thoracic artery (ITA) mobilization, orientation, and reconstruction in BITA grafting, have been published. ${ }^{1}$ The ITA is dissected from the chest wall in a skeletonized fashion free from surrounding muscle and fascia. The vein is initially dissected but subsequently removed to allow maximal length and versatility. All side branches are cauterized carefully or clipped as necessary. Since 1989, combined antegrade and retrograde infusion methods of cardioplegia have been implemented to enhance myocardial protection during the operation. Cardiopulmonary bypass was used in all operations. The operative data for propensitymatched patients, by group, are shown in Appendix E2. Operative variables were mostly comparable between matched groups with the exception of the mean distal grafts $(P=.031)$ and aortic crossclamp time $(P=.009)$ in group I. In groups II and III, the aortic crossclamp time was, as expected, significantly greater for those receiving BITA than for those receiving SITA $(P<.001)$.

\section{Data Collection and Management}

Perioperative data were obtained by prospective review of the patient's hospital record, catheterization reports, cineangiograms, and echocardiography. Follow-up information was obtained through comprehensive questionnaires and by telephone interview with surviving patients, family members, or the patient's personal physician. A Patient Registration Form and a Patient Follow-Up Form were completed for each patient in the study. Appendix E3 shows the definitions of terms.

\section{Statistical Analysis}

Demographic and clinical data are presented as frequency distributions and simple percentages. Values of continuous variables are expressed as mean \pm standard deviation. Univariate analysis of selected preoperative and postoperative discrete variables was accomplished by chi-square, continuity-adjusted chi-square analysis, or 2-tailed Fisher exact test with the appropriate degrees of freedom to test for the equality of proportions in the case of categoric variables. Two-sample $t$ tests (2-tailed) were used to test for the equality of means of continuous variables. 
TABLE 1. Comparison of preoperative variables and risk factors in propensity-matched ejection fraction groups

\begin{tabular}{|c|c|c|c|c|c|c|c|c|c|}
\hline \multirow[b]{2}{*}{ Variable } & \multicolumn{3}{|c|}{$\begin{array}{c}\text { Group I } \\
\text { matched patients } \\
\mathbf{E F}<\mathbf{0 . 3 0} \\
\end{array}$} & \multicolumn{3}{|c|}{$\begin{array}{c}\text { Group II } \\
\text { matched patients } \\
\text { EF 0.30-0.50 } \\
\end{array}$} & \multicolumn{3}{|c|}{$\begin{array}{c}\text { Group III } \\
\text { matched patients } \\
\text { EF }>0.50 \\
\end{array}$} \\
\hline & SITA & BITA & $P$ value & SITA & BITA & $P$ value & SITA & BITA & $P$ value \\
\hline No. of patients & $87(100.0)$ & $87(100.0)$ & & $448(100.0)$ & $448(100.0)$ & & $1137(100.0)$ & $1137(100.0)$ & \\
\hline Gender & & & .660 & & & .282 & & & .100 \\
\hline Male & $74(85.4)$ & 76 (87.4) & & $382(85.3)$ & 393 (87.7) & & 859 (75.5) & 892 (78.5) & \\
\hline Female & $13(14.9)$ & $11(12.6)$ & & $66(14.7)$ & $55(12.3)$ & & $278(24.5)$ & $245(21.5)$ & \\
\hline \multicolumn{10}{|l|}{ Age at operation } \\
\hline Mean \pm SD & $64.4 \pm 10.5$ & $63.2 \pm 9.4$ & .426 & $64.0 \pm 7.4$ & $64.0 \pm 8.8$ & .944 & $63.6 \pm 8.2$ & $63.7 \pm 9.4$ & .803 \\
\hline \multicolumn{10}{|l|}{ Coronary risk factors } \\
\hline Family history of CAD & $42(48.3)$ & $45(51.7)$ & 649 & $237(52.9)$ & $241(53.8)$ & .789 & $625(55.0)$ & $629(55.3)$ & .866 \\
\hline Hypertension & $15(17.2)$ & $16(18.4)$ & .843 & $153(34.2)$ & $150(33.5)$ & .832 & $409(36.0)$ & $424(37.3)$ & .514 \\
\hline Dyslipidemia & $8(9.2)$ & $8(9.2)$ & 1.000 & $74(16.5)$ & $75(16.7)$ & .929 & $161(14.2)$ & $152(13.4)$ & .584 \\
\hline Smoking history & $61(70.1)$ & $62(71.3)$ & .868 & $286(63.8)$ & $286(63.8)$ & 1.000 & $713(62.7)$ & $712(62.6)$ & .965 \\
\hline Diabetes mellitus & $29(33.3)$ & $23(26.4)$ & .320 & $145(32.4)$ & $129(28.8)$ & .246 & $292(25.7)$ & $275(24.2)$ & .410 \\
\hline \multicolumn{10}{|l|}{ Preoperative risk factors } \\
\hline Renal dysfunction & $5(5.7)$ & $5(5.7)$ & 1.000 & $24(5.4)$ & $19(4.2)$ & .435 & $43(3.8)$ & $35(3.1)$ & .357 \\
\hline Cerebrovascular disease & $5(5.7)$ & $7(8.0)$ & .550 & $24(5.4)$ & $16(3.6)$ & .196 & $47(4.1)$ & $47(4.1)$ & 1.000 \\
\hline Peripheral artery disease & $7(8.0)$ & $8(9.2)$ & .787 & $28(6.3)$ & $23(5.1)$ & .471 & $43(3.8)$ & $39(3.4)$ & .653 \\
\hline Prior myocardial infarction & $67(77.0)$ & $69(79.3)$ & .714 & $353(78.8)$ & $347(77.5)$ & .628 & $565(49.7)$ & $560(49.3)$ & .834 \\
\hline History of CHF & $29(33.3)$ & $24(27.6)$ & .410 & 89 (19.9) & $67(15.0)$ & .053 & $86(7.6)$ & $80(7.0)$ & .629 \\
\hline Unstable angina & $60(69.0)$ & $59(67.8)$ & .870 & $289(64.5)$ & $280(62.5)$ & .532 & $745(65.5)$ & $750(66.0)$ & .825 \\
\hline \multicolumn{10}{|l|}{ Coronary angiography } \\
\hline 3-vessel disease & $77(88.5)$ & $80(92.0)$ & .444 & $385(85.9)$ & $385(85.9)$ & 1.000 & $915(80.5)$ & $917(80.7)$ & .916 \\
\hline
\end{tabular}

$E F$, Ejection fraction; SITA, single internal thoracic artery; $B I T A$, bilateral internal thoracic artery; $C A D$, coronary artery disease; $C H F$, chronic heart failure; $S D$, standard deviation.

A propensity score was generated using a logistic regression model based on 15 covariates as independent variables in each of the study groups. Appendix E4 shows a listing of covariates used to generate a propensity score. The treatment type (SITA vs BITA) was used as a binary dependent variable. The resulting propensity score indicated that a patient underwent BITA rather than SITA CABG. Patients receiving BITA were then matched to patients receiving SITA in a 1:1 ratio using an optimal matching algorithm. This approach minimized the overall distance between observations and was conducted using Mahalanobis distance within propensity score calipers (no matches outside the calipers).

To determine the predictors of hospital mortality, a hierarchic logistic regression model was developed using preoperative and intraoperative variables (Appendix E5 shows the list of variables used to generate the model). To identify risk factors associated with late mortality, a univariate analysis of preoperative, intraoperative, and postoperative variables was performed. Variables achieving statistical significance $(P<.050)$ were then used to create a Cox proportional hazards regression model to discern the influence of multiple clinical variables on late survival. Covariates with borderline significance in the univariate analysis and clinical relevance were also included in the model. Regression coefficients and odds ratios with $95 \%$ confidence intervals were calculated to determine the relative influence of each covariate on the survivor function. Coefficients were computed by the method of maximum likelihood (Appendix E6 shows the list of variables used in the Cox regression).

Actuarial survival estimates (including operative deaths) were calculated according to the Kaplan-Meier method using time zero as the date of operation and late death as the end point (with variability expressed as the standard error of the mean). The equality of survival distribution was tested with the log-rank algorithm. All $P$ values reported are 2-sided and not adjusted for multiple testing. All analyses were performed using Number Cruncher Statistical Systems software (NCSS, Kaysville, Utah).

\section{RESULTS}

A series of postoperative complications are documented from the dataset and reported in Table 2. The rate of no complications for SITA versus BITA recipients in group I was similar $(72.4 \%$ vs $82.8 \% ; P=.102)$. In group II, the rate of no complications for SITA versus BITA was also similar $(82.6 \%$ vs $81.5 \% ; P=.664)$. A comparison of group I BITA recipients with group III BITA recipients generated no significant difference $(82.8 \%$ vs $86.9 \%$; $P=.275$ ). An additional comparison of BITA recipients in groups II and III revealed that a greater proportion of group III BITA recipients experienced no in-hospital complications $(81.5 \%$ vs $86.9 \% ; P=.006)$. Incidence of no complications in SITA versus BITA recipients in group III approached statistical significance $(84.1 \%$ vs $86.9 \%$; $P=.057)$. For the entire series, the incidence of no complications was highest in group III BITA recipients $(86.9 \%)$.

On review of the individual morbidities across the 3 groups, respiratory insufficiency necessitating prolonged mechanical ventilation was the most common complication for patients in groups I and II. In group III, myocardial infarction appeared with the greatest frequency in both SITA and BITA recipients.

The hospital mortality rate for all SITA recipients in the series was $4.6 \%(107 / 2340)$ and $2.6 \%$ (57/2197) for all BITA recipients $(P<.001)$. The overall in-hospital 
TABLE 2. Comparison of postoperative complications in matched ejection fraction groups

\begin{tabular}{|c|c|c|c|c|c|c|c|c|c|c|c|c|c|c|c|}
\hline \multirow[b]{2}{*}{ Complication* } & \multicolumn{5}{|c|}{$\begin{array}{c}\text { Group I } \\
\text { matched patients } \\
\mathbf{E F}<\mathbf{0 . 3 0}\end{array}$} & \multicolumn{5}{|c|}{$\begin{array}{c}\text { Group II } \\
\text { matched patients } \\
\text { EF 0.30-0.50 }\end{array}$} & \multicolumn{5}{|c|}{$\begin{array}{c}\text { Group III } \\
\text { matched patients } \\
\text { EF }>0.50\end{array}$} \\
\hline & \multicolumn{2}{|c|}{ SITA } & \multicolumn{2}{|c|}{ BITA } & \multirow[t]{2}{*}{$P$ value } & \multicolumn{2}{|c|}{ SITA } & \multicolumn{2}{|c|}{ BITA } & \multirow[t]{2}{*}{$P$ value } & \multicolumn{2}{|c|}{ SITA } & \multicolumn{2}{|c|}{ BITA } & $P$ value \\
\hline No. of patients & & $100.0)$ & & 100.0) & & 448 & 100.0) & 448 & 100.0) & & 113 & $(100.0)$ & 1137 & $(100.0)$ & \\
\hline No complications & 63 & $(72.4)$ & 72 & $(82.8)$ & .102 & 370 & (82.6) & 365 & $(81.5)$ & .664 & 956 & $(84.1)$ & 988 & $(86.9)$ & .057 \\
\hline Reoperation for bleeding & 7 & $(8.0)$ & 0 & $(0.0)$ & .007 & 8 & (1.8) & 6 & (1.3) & .590 & 37 & $(3.3)$ & 27 & (2.4) & .205 \\
\hline Low cardiac output & 8 & $(9.2)$ & 4 & $(4.6)$ & .231 & 12 & (2.7) & 14 & (3.1) & .691 & 24 & $(2.1)$ & 22 & (1.9) & .766 \\
\hline Cardiac arrest & 7 & $(8.0)$ & 3 & (3.4) & .193 & 13 & (2.9) & 20 & $(4.5)$ & .214 & 33 & $(2.9)$ & 31 & $(2.7)$ & .800 \\
\hline Renal dysfunction & 3 & (3.4) & 3 & (3.4) & 1.000 & 17 & (3.8) & 17 & (3.8) & 1.000 & 32 & $(2.8)$ & 23 & (2.0) & .219 \\
\hline Myocardial infarction & 5 & $(5.7)$ & 1 & (1.1) & .097 & 25 & (5.6) & 18 & $(4.0)$ & .274 & 74 & $(6.5)$ & 59 & $(5.2)$ & .180 \\
\hline Stroke & 2 & $(2.3)$ & 1 & (1.1) & .560 & 10 & $(2.2)$ & 13 & (2.9) & .526 & 15 & $(1.3)$ & 8 & $(0.7)$ & .142 \\
\hline Respiratory insufficiency & 11 & $(12.6)$ & 9 & $(10.3)$ & .635 & 26 & $(5.8)$ & 35 & (7.8) & .233 & 43 & $(3.8)$ & 51 & $(4.5)$ & .400 \\
\hline Gastrointestinal & 1 & $(1.1)$ & 1 & (1.1) & 1.000 & 9 & (2.0) & 7 & (1.6) & .614 & 22 & $(1.9)$ & 29 & (2.6) & .322 \\
\hline Sternal wound infection & 2 & $(2.3)$ & 2 & (2.3) & 1.000 & 5 & (1.1) & 7 & (1.6) & .561 & 13 & $(1.1)$ & 17 & $(1.5)$ & .462 \\
\hline
\end{tabular}

$E F$, Ejection fraction; SITA, single internal thoracic artery; BITA, bilateral thoracic artery. *Numbers in parentheses are percentages.

mortality rate for the series was $3.6 \%$ (164/4537). Hospital mortality increased with decreasing EF. Table 3 shows the hospital mortality rates for unmatched and matched patient groups and by procedure. Although statistical differences in hospital mortality were noted in unmatched groups II and III, there was no difference in any of the matched groups.

To identify independent correlates of hospital mortality, 17 preoperative and intraoperative variables were entered into a forward stepwise logistic regression model for unmatched patients (Appendix E7). In group I, age at operation $(P=.013)$ and use of the intra-aortic balloon pump inserted preoperatively $(P=.005)$ were correlated with in-hospital mortality. In group II, age at operation $(P=.002)$, congestive heart failure $(P=.014)$, intraaortic balloon pump inserted preoperatively $(P<.001)$, and aortic crossclamp time $(P=.012)$ were associated with in-hospital mortality. In group III, age at operation $(P<.001)$, intra-aortic balloon pump inserted preoperatively $(P<.001)$, and aortic crossclamp time $(P<.001)$ were identified as predictors of hospital mortality. Of note, use of BITA grafting was not predictive of hospital mortality in any group.

Initial clinical follow-up data were collected for $96.4 \%$ patients (4373/4537) discharged from the hospital: 98.2\% (2299/2340) SITA and 96.6\% (2125/2197) BITA. The average duration of follow-up for unmatched hospital survivors in group I was 7.0 years (range, 6 weeks to 21.5 years) in SITA recipients and 7.9 years (range, 6 weeks to 30.5 years) in BITA recipients. The cumulative follow-up was 1023.8 patient-years for the SITA group and 691.4 patient-years for the BITA group. For group II, the average duration of follow-up for unmatched hospital survivors was 9.4 years (range, 6 weeks to 31.6 years) in SITA recipients and 11.4 years (range, 6 weeks to 31.7 years) in BITA recipients. The cumulative follow-up was 6149.4 patient-years for the SITA group and 6868.5 patient-years for the BITA group. The average duration of follow-up for unmatched hospital survivors in group III was 11.5 years (range, 6 weeks to 30.9 years) in SITA recipients and 13.0 years (range, 6 weeks to 32.1 years) in BITA recipients. The cumulative follow-up was $17,758.8$ patient-years for the SITA group and 19,606.0 patient-years for the BITA group.

To identify independent predictors of late death, a Cox proportional hazards regression model was created using 30 preoperative, intraoperative, and postoperative variables to measure the effects of various prognostic factors on time to response (operation to late death). Cox regression analysis demonstrated the independence of a series of covariates associated with late mortality for each of the unmatched groups (Table 4). Of note, SITA versus BITA use was an independent predictor of late mortality in both groups II and III, but not in group I.

The actuarial survival data for matched SITA and BITA recipients by groups are shown in Figure 1. Appendix E8 shows the actuarial survival curves of unmatched patients. Survivals were ( \pm the standard error of the mean) $48.3 \%$ $\pm 4.2 \%$ at 7 years and $20.7 \% \pm 3.6 \%$ at 14 years in unmatched group I SITA recipients and $51.7 \% \pm 5.4 \%$ at 7 years and $26.7 \% \pm 4.9 \%$ at 14 years in BITA recipients $(P=.289)$. The median survival for SITA was 6.4 years and 7.0 years for BITA. Survivals were $57.0 \% \pm 5.3 \%$ at 7 years and $26.6 \% \pm 5.1 \%$ at 14 years in matched group I SITA recipients and $51.7 \% \pm 5.4 \%$ at 7 years and $26.7 \% \pm 4.9 \%$ at 14 years in BITA recipients $(P=.934)$. The median survival was 8.5 years for SITA recipients and 7.0 for BITA recipients.

Survivals were $49.4 \% \pm 2.0 \%$ at 10 years and $15.0 \% \pm$ $2.0 \%$ at 20 years in unmatched group II SITA recipients and $66.2 \% \pm 2.0 \%$ at 10 years and $36.8 \% \pm 2.8 \%$ at 20 years for BITA recipients $(P<.001)$. The median survival for SITA recipients was 9.9 years and 14.6 years for BITA recipients. Survivals were $57.7 \% \pm 2.3 \%$ at 10 years and 
TABLE 3. Comparison of hospital mortality by patient group

\begin{tabular}{crrrr}
\hline & \multicolumn{1}{c}{ SITA } & & BITA & \\
\cline { 2 - 2 } Group & N $(\%)$ & & N (\%) & P value \\
\hline Group I, EF $<0.30$ & & & \\
$\quad$ Unmatched patients & $17 / 146(11.6)$ & & $6 / 87(6.9)$ & .240 \\
$\quad$ Matched patients & $9 / 87(10.3)$ & & $6 / 87(6.9)$ & .418 \\
Group II, EF 0.30-0.50 & & & \\
$\quad$ Unmatched patients & $37 / 656(5.6)$ & & $20 / 600(3.3)$ & .050 \\
$\quad$ Matched patients & $21 / 448(4.7)$ & & $20 / 448(4.5)$ & .873 \\
Group III, EF $>0.50$ & & & \\
$\quad$ Unmatched patients & $53 / 1538(3.4)$ & & $31 / 1510(2.1)$ & .019 \\
$\quad$ Matched patients & $36 / 1,137(3.2)$ & $23 / 1,137(2.0)$ & .086 \\
\hline
\end{tabular}

SITA, Single internal thoracic artery; BITA, bilateral internal thoracic artery; $E F$, ejection fraction.
$19.2 \% \pm 2.5 \%$ at 20 years in matched group II SITA recipients and $62.0 \% \pm 2.3 \%$ at 10 years and $33.1 \% \pm 3.4 \%$ at 20 years in BITA recipients $(P=.016)$. The median survival for SITA recipients was 11.6 years and 13.6 years for BITA recipients.

Survivals were $45.7 \% \pm 1.3 \%$ at 14 years and $11.1 \% \pm$ $3.3 \%$ at 28 years in unmatched group III SITA recipients and $62.1 \% \pm 1.3 \%$ at 14 years and $24.4 \% \pm 3.1 \%$ at 28 years in BITA recipients $(P<.001)$. The median survival for SITA recipients was 12.8 years and 17.2 years for BITA recipients. survivals were $54.4 \% \pm 1.5 \%$ at 14 years and $14.4 \% \pm 4.2 \%$ at 28 years in matched group III SITA recipients and $59.4 \% \pm 1.5 \%$ at 14 years and $19.5 \%$

TABLE 4. Multivariate analysis of demographic and preoperative clinical variables influencing late mortality by Cox regression analysis in unmatched ejection fraction groups

\begin{tabular}{|c|c|c|c|c|}
\hline Group/predictor & $\beta$ Estimate & SE & HR $(95 \%$ CI $)$ & $P$ value* \\
\hline \multicolumn{5}{|l|}{ Group I, EF < 0.30} \\
\hline \multicolumn{5}{|l|}{ Preoperative } \\
\hline Age at operation & 0.038 & 0.0085 & $1.0(1.0-1.0)$ & $<.001$ \\
\hline Pulmonary insufficiency & 0.775 & 0.2291 & $2.2(1.4-3.4)$ & .002 \\
\hline Surgical urgency & 0.417 & 0.1762 & $1.5(1.1-2.1)$ & .015 \\
\hline \multicolumn{5}{|l|}{ Group II, EF 0.30-0.50 } \\
\hline \multicolumn{5}{|l|}{ Preoperative } \\
\hline Age at operation & 0.060 & 0.0045 & $1.1(1.1-1.1)$ & $<.001$ \\
\hline Congestive heart failure & 0.298 & 0.0938 & $1.3(1.1-1.6)$ & .002 \\
\hline Cerebrovascular disease & 0.569 & 0.1613 & $1.8(1.3-2.4)$ & .001 \\
\hline Diabetes & 0.342 & 0.0828 & $1.4(1.2-1.7)$ & $<.001$ \\
\hline Peripheral arterial disease & 0.443 & 0.1436 & $1.6(1.2-2.1)$ & .004 \\
\hline Renal dysfunction (creatinine $\geq 2.0 \mathrm{mg} / \mathrm{dL}$ ) & 0.514 & 0.1559 & $1.7(1.2-2.3)$ & .002 \\
\hline Smoking history & 0.211 & 0.0778 & $1.3(1.1-1.4)$ & .006 \\
\hline Intraoperative & & & - & \\
\hline SITA used & -0.214 & 0.0787 & $0.8(0.7-0.9)$ & .007 \\
\hline \multicolumn{5}{|l|}{ Postoperative } \\
\hline Stroke & 0.606 & 0.2354 & $1.8(1.2-2.9)$ & .018 \\
\hline Renal dysfunction (creatinine $\geq 2.0 \mathrm{mg} / \mathrm{dL}$ ) & 0.602 & 0.2055 & $1.8(1.2-2.7)$ & .007 \\
\hline \multicolumn{5}{|l|}{ Group III, EF $>0.50$} \\
\hline \multicolumn{5}{|l|}{ Preoperative } \\
\hline Age at operation & 0.072 & 0.0032 & $1.1(1.1-1.1)$ & $<.001$ \\
\hline Congestive heart failure & 0.452 & 0.0859 & $1.6(1.3-1.9)$ & $<.001$ \\
\hline Cerebrovascular disease & 0.387 & 0.1112 & $1.5(1.2-1.8)$ & .001 \\
\hline Diabetes & 0.507 & 0.0569 & $1.7(1.5-1.9)$ & $<.001$ \\
\hline Family history of coronary artery disease & -0.110 & 0.0510 & $0.9(0.8-1.0)$ & .031 \\
\hline Left main disease $(>0.5)$ & 0.202 & 0.0609 & $1.2(1.1-1.4)$ & .001 \\
\hline Peripheral arterial disease & 0.305 & 0.1124 & $1.4(1.1-1.7)$ & .009 \\
\hline Prior myocardial infarction & 0.229 & 0.0505 & $1.3(1.1-1.4)$ & $<.001$ \\
\hline Renal dysfunction (creatinine $\geq 2.0 \mathrm{mg} / \mathrm{dL}$ ) & 0.366 & 0.1277 & $1.4(1.1-1.9)$ & $<.001$ \\
\hline Smoking history & 0.223 & 0.0524 & $1.2(1.1-1.4)$ & $<.001$ \\
\hline \multicolumn{5}{|l|}{ Intraoperative } \\
\hline SITA used & -0.211 & 0.0532 & $0.8(0.7-0.9)$ & $<.001$ \\
\hline Crossclamp time & 0.002 & 0.0011 & $1.0(1.0-1.0)$ & .047 \\
\hline \multicolumn{5}{|l|}{ Postoperative } \\
\hline Cardiac arrest & 0.649 & 0.1787 & $1.9(1.3-2.7)$ & .001 \\
\hline Pulmonary insufficiency & 0.363 & 0.1183 & $1.4(1.1-1.8)$ & .004 \\
\hline Renal dysfunction (creatinine $\geq 2.0 \mathrm{mg} / \mathrm{dL}$ ) & 0.856 & 0.1516 & $2.4(1.7-3.2)$ & .007 \\
\hline
\end{tabular}

$S E$, Standard error; $H R$, hazard ratio; $C I$, confidence interval; $E F$, ejection fraction; $S I T A$, single internal thoracic artery. *Only significant variables $(P<.050)$ are listed. 


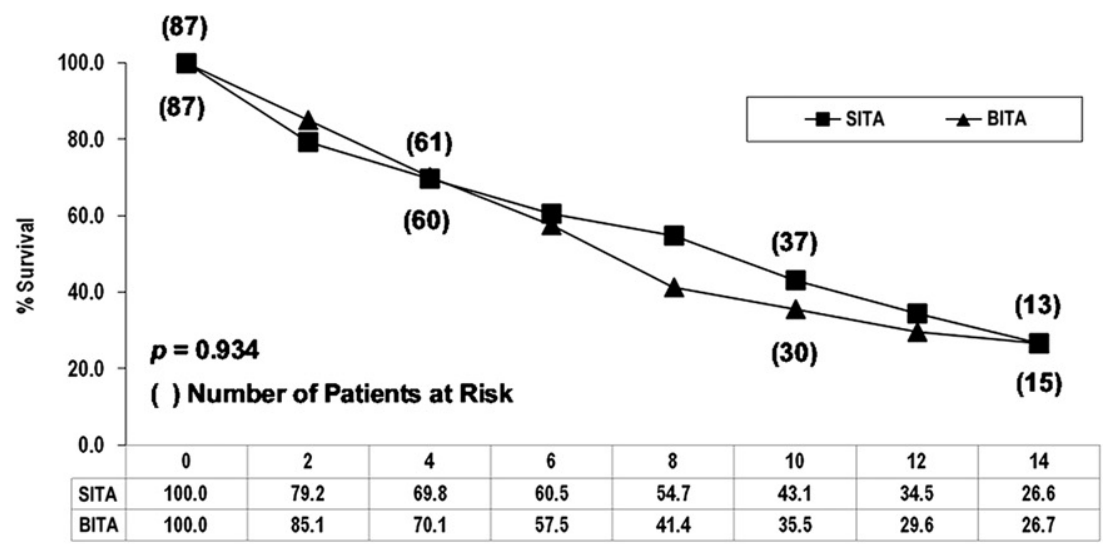

A

Years After Operation

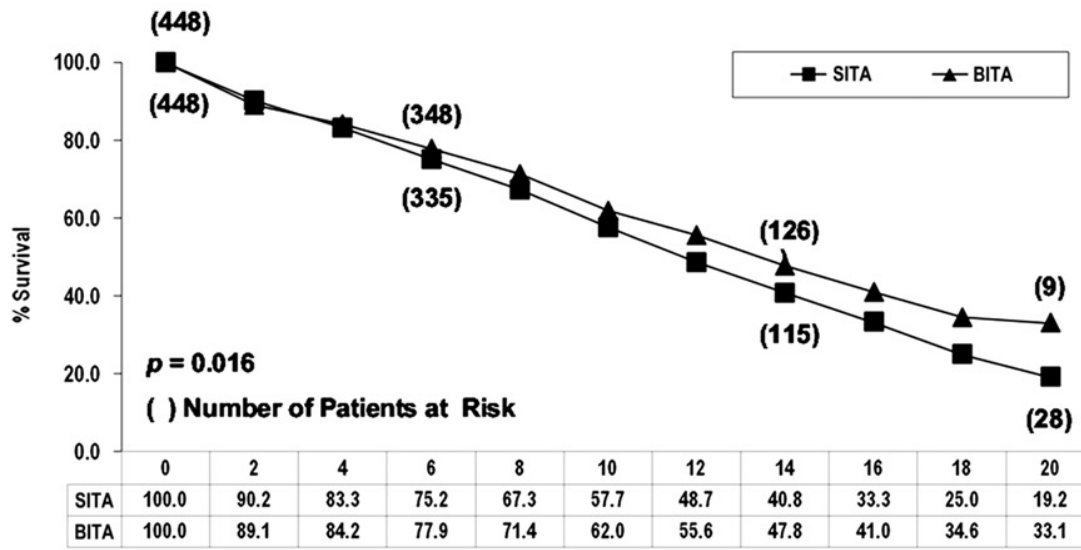

B

Years After Operation

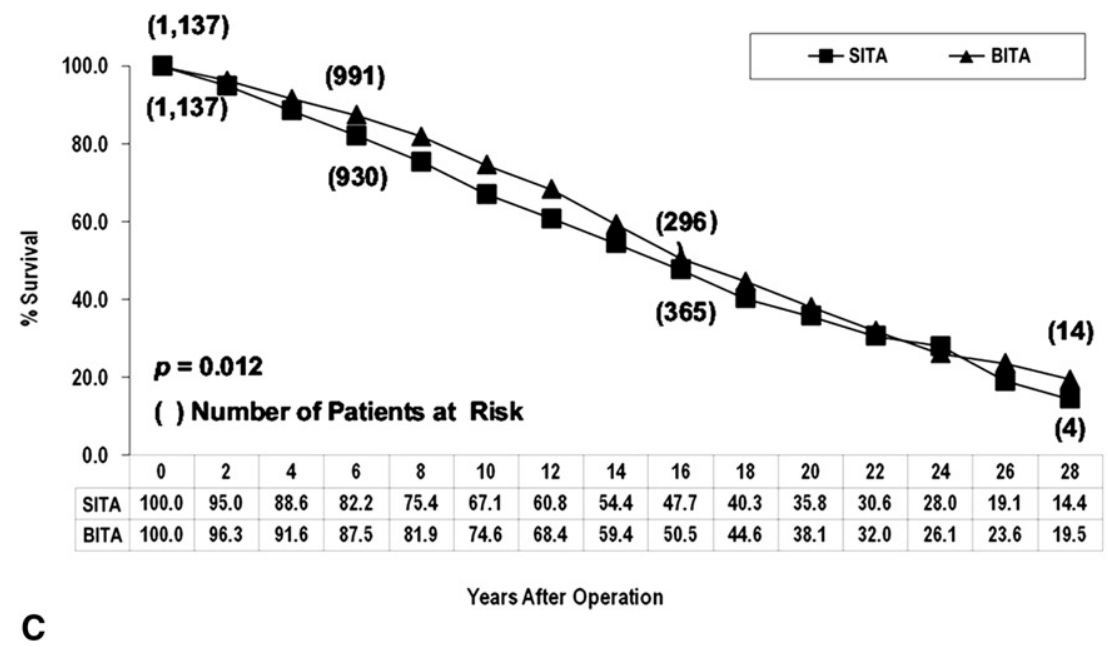

FIGURE 1. A, Matched group I SITA and BITA recipients (EF < 0.30). B, Matched group II SITA and BITA recipients (EF 0.30-0.50). $\mathrm{C}$, Matched group III SITA and BITA recipients (EF > 0.50). SITA, Single internal thoracic artery; BITA, bilateral internal thoracic artery; $E F$, ejection fraction. 
$\pm 3.4 \%$ at 28 years in BITA recipients $(P=.012)$. The median survival for SITA recipients was 15.4 years and 16.0 years for BITA recipients. The equality of survival distribution demonstrated significant differences between unmatched and matched group II and group III SITA versus BITA recipients.

To further assess the impact of date of surgery on survival, the distribution of date of surgery was compared in each of the 3 groups of matched patients. It was determined that there was no significant difference in the distribution of date of surgery in groups I and II. Therefore, inclusion of the date of surgery in the matching algorithm would not have changed the results. However, in group III, using chisquare analysis, there was a statistically significant difference between the SITA and BITA groups in the distribution of surgery date, with more of the BITA recipients undergoing operation in the more recent years $(P=.001)$ Therefore, we redid the propensity matching for this group including the data of surgery in the model to achieve groups that were well matched with regard to the date of surgery and all of the other variables outlined in the model. This generated a propensity score that was then used in the optimal matching algorithm to create comparable groups. To assess survival, a Kaplan-Meier curve was created for each of the groups (SITA vs BITA), and a significant difference favoring the BITA group was achieved using the log-rank test $(P=.029)$

\section{DISCUSSION}

During the past 20 years, $\mathrm{OM}$ in patients undergoing CABG with left ventricular dysfunction has continued to decrease but remains modestly greater than in those with normal systolic function. ${ }^{7-12}$ Some studies have reported intermediate-term follow-up with 5- and 7-year late survival ranging from $72 \%$ to $63 \% .^{11,12,14-16} \mathrm{~A}$ recent study of 302 patients with left ventricular dysfunction reported an $\mathrm{OM}$ of $5.3 \%$ and a 10 -year survival of $63 \% \pm 4 \%{ }^{13}$ SITA grafting was prevalent in these studies, but the impact of BITA grafting has rarely been described.

Our study is unique in the broad application of BITA grafting (approaching $48 \%$ of the study population), the matching of patient cohorts receiving SITA or BITA grafting in the 3 study groups, and the 30-year follow-up period. The main findings of the present study included a modestly greater $\mathrm{OM}$ in patients with left ventricular dysfunction compared with those with normal systolic function, which is consistent with the literature. Within matched groups of patients receiving SITA or BITA grafting, there was no significant difference in OM or complications. Late survival was significantly enhanced with BITA grafting in matched patients in group III $(P=.012)$ and group II $(P=.016)$. BITA grafting exerted no influence in group I, possibly because of the small sample size or increased severity of left ventricular dysfunction.
In group II, the 10-year survival of patients receiving BITA grafting was $62 \% \pm 2 \%$ compared with $58 \% \pm$ $3 \%$ in those receiving SITA grafting. At 20 years in group II, patients receiving BITA grafting had a late survival of $33 \% \pm 3.4 \%$ compared with those receiving SITA grafting of $19.1 \% \pm 2.5 \%$. This increased divergence is significant. It is noteworthy that BITA grafting in group II at 20 years of follow-up yields an outcome that is similar to the 20-year late survival of group III patients receiving SITA grafting $(35.8 \% \pm 1.7 \%)$.

It seems that a patient with reduced EF receiving BITA compared with SITA grafting demonstrates a survival advantage that increases over time. This suggests that the real benefit of BITA grafting is determined by a patient's age and "survival probability," which may correlate with certain comorbidities. Others have noted that diabetes, chronic renal dysfunction, and ventricular arrhythmias are predictors of late mortality in patients with left ventricular dysfunction. ${ }^{13,17-19}$ This is consistent with our findings. Recent data have demonstrated the efficacy of implantable cardiodefibrillators in reducing late mortality in patients with left ventricular dysfunction. ${ }^{20}$ Although previous studies have failed to demonstrate any single comorbidity that removes the long-term survival benefit of BITA grafting, ${ }^{6}$ our findings strongly suggest that patients with a life expectancy of 1 to 2 decades should receive BITA grafting.

In view of the clinical advantages of BITA grafting demonstrated in the literature, its infrequent use in clinical practice is remarkable. The Society of Thoracic Surgeons National Adult Cardiac Surgery Database reports that only $4 \%$ of CABG procedures involve the use of BITA grafting. ${ }^{21}$ Several concerns influence surgical decision making. The adequacy of multiple ITA grafts to maintain necessary hemodynamic parameters in the immediate postoperative period has been questioned. ${ }^{22}$ The current study refutes this concern because there was no difference in $\mathrm{OM}$ or postoperative infarction between matched patients receiving BITA or SITA in all 3 study groups. There are reports of an increased incidence of sternal wound infection, particularly in diabetic patients receiving BITA grafting. ${ }^{23,24}$ Increased mediastinal bleeding and pulmonary morbidity have also been reported with BITA grafting. ${ }^{25}$ In our study, there was no difference in sternal wound infection among matched patients (including diabetic patients) receiving BITA or SITA grafting. This discrepancy may be explained by our technique of skeletonizing the ITA, which preserves the lymphatic vessels and more of the blood supply to the sternum, compared with the more commonly used technique of ITA harvesting with a wide pedicle. $^{26}$ Although there was no difference in pulmonary complications in matched patients receiving BITA or SITA grafting in our study, contemporary criteria, which measure the number of postoperative hours of mechanical 
ventilation, and total blood product use may encourage surgeons to perform shorter operations with SITA grafting.

Given the current focus on perioperative rather than longterm outcomes, in a setting of increasingly complex patient comorbidities, surgeons may be more likely to perform simpler operations whenever possible. The left ITA bypass to the left anterior descending artery, the most strategic graft in promoting longevity in the majority of patients, can be accomplished easily. In contrast, right ITA grafting can be technically challenging. The usual practice of a wide pedicle at ITA harvesting minimizes the length available to perform a tension-free anastomosis. Greater attention to the orientation of the right ITA graft relative to the pericardium, superior vena cava, aorta, and pulmonary artery and the coronary artery target is needed to prevent twisting or compression of the conduit. Despite a recent report from our registry demonstrating no difference in clinical outcome in matched groups of patients receiving in situ right ITA to the left coronary system (obtuse marginal branch, diagonal, or left anterior descending arteries) or the right coronary system, ${ }^{27}$ many surgeons remain uncertain as to the appropriate coronary artery target vessel for right ITA grafting. Successful right ITA grafting for most surgeons requires the experience of a learning curve and more frequent than just occasional use in $\mathrm{CABG}$ procedures.

\section{Limitations}

This study has the inherent limitations of being retrospective and nonrandomized. It is impossible to define the subtlety of clinical judgment in determining which patients received BITA or SITA grafting. Nevertheless, optimal matching with propensity scoring is a helpful tool in validating the conclusions of this study. The guidelines in current practice, which include postoperative patients being discharged with a medical regimen of beta-blockers, angiotensin-converting enzyme inhibitors, platelet antagonists, and lipid-lowering agents, and greater emphasis on lifestyle modifications and risk factors may improve the long-term outcome of patients undergoing CABG, thereby potentially ameliorating the benefits observed. Moreover, although BITA grafting was widely applied in this patient cohort, there remains the possibility that a similar approach with current higher-risk patients in a setting of improved operative and perioperative care may not yield similar results.

\section{CONCLUSIONS}

Despite its inherent limitations, this study provides compelling evidence that BITA compared with SITA grafting provides enhanced long-term survival with no increase in OM or morbidity for comparable patients with both normal and reduced left ventricular function. BITA grafting should be the operation of choice in patients with a life expectancy beyond 1 to 2 decades.
The authors thank Debra D. Guest, EdD, for technical assistance in the preparation of this report.

\section{References}

1. Galbut DL, Traad EA, Dorman MJ, et al. Twelve-year experience with bilateral internal mammary artery grafts. Ann Thorac Surg. 1985;40:264-70.

2. Pick AW, Orzulak TA, Anderso BJ, Schaff HV. Single versus bilateral internal mammary artery grafts: 10-year outcome analysis. Ann Thorac Surg. 1997;64 599-605.

3. Lytle BW, Blackstone EH, Sabik JF, Houghtaling P, Loop FD, Cosgrove DM. The effect of bilateral internal thoracic artery grafting on survival during 20 postoperative years. Ann Thorac Surg. 2004;78:2005-14.

4. Taggart DP, D'Amico R, Altman DG. Effect of arterial revascularization on survival: a systematic review of studies comparing bilateral and single internal mammary arteries. Lancet. 2001;358:870-5.

5. Rizzoli G, Shiavon L, Bellini P. Does the use of bilateral internal mammary artery (IMA) grafts provide incremental benefit relative to use of a single IMA graft? A meta-analysis approach. Eur J Cardiothorac Surg. 2002;22:781-6.

6. Kurlansky PA, Traad EA, Dorman MJ, Galbut DL, Zucker M, Ebra G. Thirtyyear follow-up defines survival benefit for second internal mammary artery in propensity-matched groups. Ann Thorac Surg. 2010;90:101-8.

7. Filsoufi F, Rahmanian PB, Castillo JG, Chikwe J, Kini AS, Adams DH. Results and predictors of early and late outcomes of coronary artery bypass grafting in patients with severely depressed left ventricular function. Ann Thorac Surg. 2007;84:808-16

8. Soliman Hamad MA, Tan ME, vanStraten AH, vanZundert AA, Schonberger JP. Long-term results of coronary artery bypass grafting in patients with left ventricular dysfunction. Ann Thorac Surg. 2008;85:488-93.

9. Topkara VK, Cheema FH, Kesavaramanujam S. Coronary artery bypass grafting in patients with low ejection fraction. Circulation. 2005;112(Suppl 1):I344-50.

10. Tan J, Kejriwal N, Vasudevan A, Maria PL, Alvarez JM. Coronary bypass surgery for patients with chronic poor preoperative left ventricular function $(\mathrm{EF}<30 \%)$ : 5-year follow-up. Heart Lung Circ. 2006;15:130-6.

11. Appoo J, Norris C, Merali S, et al. Long-term outcomes of isolated coronary artery bypass surgery in patients with severe left ventricular dysfunction. Circulation. 2004;11:II13-7.

12. Langenburg SE, Buchanan SA, Blackbourne LH, et al. Predicting survival after coronary revascularization for ischemic cardiomyopathy. Ann Thorac Surg. 1995;60:1193-7.

13. Nardi P, Pellegrino A, Scafuri A, et al. Long term outcome of coronary artery bypass grafting in patients with left ventricular dysfunction. Ann Thorac Surg. 2009;87:1401-8

14. Elefteriades JA, Morales DL, Gradel C, Tollis G, Levi E, Zaret BL. Results of coronary artery bypass grafting by a single surgeon in patients with left ventricular ejection fraction $<$ or $=30 \%$. Am J Cardiol. 1997;79:1573-8.

15. Trachiotis GD, Weintraub WS, Johnston TS, Jones EL, Guyton RA, Craver JM Coronary artery bypass grafting in patients with advanced left ventricular dysfunction. Ann Thorac Surg. 1998;66:1632-9.

16. Luciani GB, Montalbano G, Casali G, Mazzucco A. Predicting long-term results after myocardial revascularization in ischemic cardiomyopathy. J Thorac Cardiovasc Surg. 2000;120:478-89.

17. Domanski M, Krausse-Steinrauf H, Deedwania P, et al. The effect of diabetes on outcomes of patients with advanced heart failure in the BEST trial. J Am Coll Cardiol. 2003;42:914-22.

18. Rajakaruna C, Rogers CA, Suranimala C, Angelini GD, Ascione R. The effect of diabetes mellitus on patients undergoing coronary surgery: a risk adjusted analysis. J Thorac Cardiovasc Surg. 2006;132:802-10.

19. Hillis GS, Zehr KJ, Williams AW, et al. Outcome of patients with low ejection fraction undergoing coronary artery bypass grafting: renal function and mortality after 3.8 years. Circulation. 2006;114(Suppl I):I414-9.

20. Goldenberg I, Moss AJ, McNitt S, et al. Time dependence of defibrillator benefit after coronary revascularization in the Multicenter Automatic Defibrillator Implantation Trial (MADIT)-II. J Am Coll Cardiol. 2006;47:1811-7.

21. Tabata M, Grab JD, Khalpey Z, et al. Prevalence and variability of internal mammary artery graft use in contemporary multivessel coronary artery bypass surgery. Circulation. 2009; 120:935-40

22. Spence PA, Montgomery WD, Santamore WP. High flow demand on small arterial coronary bypass conduits promotes graft spasm. J Thorac Cardiovasc Surg. 1995; 110:952-62. 
23. The Parisian Mediastinitis Study Group. Risk factors for deep sternal wound in fection after sternotomy: a prospective multi-center study. J Thorac Cardiovasc Surg. 1996;111:1200-7.

24. Savage EB, Grab JD, L'Brien SM, et al. Use of both internal thoracic arteries in diabetic patients increases deep sternal wound infection. Ann Thorac Surg. 2007; 83:1002-7.

25. Gansera B, Schidtler F, Gillrath G, et al. Does bilateral ITA grafting increase perioperative complications? Outcomes of 4462 patients with bilateral versus 4202 patients with single ITA bypass. Eur J Cardiothorac Surg. 2006;30:318-23.

26. Kamiya H, Akhyari P, Martens A, Karck M, Haverich A, Lichtenberg A. Sternal microcirculation after skeletonized versus pedicled harvesting of the internal thoracic artery: a randomized study. J Thorac Cardiovasc Surg. 2006;135:32-7.

27. Kurlansky PA, Traad EA, Dorman MJ, Galbut DL, Zucker M, Ebra G. Location of the second internal mammary graft does not influence outcome of coronary artery bypass grafting. Ann Thorac Surg. 2011;91:1378-84.

\section{Discussion}

Dr Anthony Furnary (Portland, Ore). Dr Galbut, you and your coauthors have presented a nonrandomized series of BITA and SITA groups and divided them into terciles of EF. Propensity matching was done using 14 preoperative variables, and both raw and unmatched were presented. There was a 14-year follow-up in group I, less than $30 \%$, and no differences in operative or survival were seen. There were survival differences in the group with $30 \%$ to $50 \% \mathrm{EF}$ and the group with greater than $50 \% \mathrm{EF}$. In the reduced group with $30 \%$ to $50 \% \mathrm{EF}$, there was a 22 -year followup and a raw mortality difference of $17 \%$ at 10 years, which amounted to approximately a 5-year difference in median survival in the unmatched population. Now when the groups were propensity matched, those numbers decreased from $17 \%$ at 10 years to $4 \%$ at 10 years and the median survival decreased from 5 years to approximately 2 years. The number of patients who are left at the end of the whole thing at 20 years was less than $5 \%$ of the patient population, and there are only 37 matched patients at 20 years. I do not think we can make any statistically valid conclusions on those data. In the normal EF group and the greater than $50 \% \mathrm{EF}$ group, there was a 28 -year follow-up with a raw mortality difference of approximately $16 \%$ at 10 years and $12 \%$ at 20 years, which amounted to a $4.4 \%$ difference in median survival. Now once again when the groups were propensity matched using those 14 characteristics, the differences were markedly reduced again from $17 \%$ to $7 \%$ at 10 years and from $12 \%$ to $2 \%$ at 20 years, and the median survival was now down to 7 months when the propensity matching was carried out. So statistically speaking, as we all know with nonrandomized and retrospective studies, when there are significant differences in the raw outcomes that become smaller and smaller with the more matching and risk adjustment we do, we really have to look closely at the risk adjustment techniques and the statistical techniques to find out if there is anything we missed that might account for the remaining differences. Because retrospective studies, as you know, cannot prove causality, we have to take a critical look at that. There are at least 2 variables that may not have been accounted for in this incredible study that may have had an impact on long-term survival. The 2 things that I looked at in your data (and I appreciate the article in advance) are year of operation and operating surgeon or operating center. Year of operation is important because the salutary effects of newer adjunctive treatments that came to the fore over the 22 years of this study between 1972 and 1994 on long-term survival are significant, such as myocardial protection techniques, the advent of statins, and the use of beta-blockers, angiotensin-converting enzyme inhibitors, and implantable cardioverter defibrillators to prolong survival (especially for those with lower EF). The year of operation might be an important piece to put in there to mitigate some of those factors. I have 5 questions for you.

What was the distribution of patients with SITA versus BITA over time? Were there more patients with a SITA operated on earlier? Obviously you were a pioneer in this area, but what about the other centers and surgeons? Is it possible that if there were more SITA cases operated on earlier, some of these adjunctive therapies might account for some of the differences in those SITA versus BITA?

Dr Galbut. The article is extensive in the statistical analyses, which in all valuations are significant, although I agree that the percentage may not be large as we go up to 20+ years. Many shortcomings exist in this study, all of which were mentioned and alluded to in the article, and we are now looking at age. Age is perhaps the most important factor, where if you follow patients longer you see the value of the BITA grafting, and I believe it is greater in the moderately impaired EF group, $30 \%$ to $50 \%$, than in patients with normal EF.

In regard to your specific question, at the time of this study, primarily from 1985 to 1996 , all of the surgeons were together in 1 institution, and then as our community changed and our institution proliferated into several, I can only comment anecdotally about my colleagues. Currently the majority have gotten away from BITA grafting. I don't know if that answers your question, but during the time from 1985 to 1994 , almost every year $45 \%$ to $50 \%$ of patients had BITA grafts. It is unusual in that the broad application is not seen in other institutions, and it was inspired by our group having a major interest in this area.

Dr Furnary. Would it be pretty simple to add the year of operation to your propensity matching?

Dr Galbut. Yes.

Dr Furnary. I think you should try that, and it might mitigate some of those points that we brought up. Was there any difference in operating surgeons; so this was 1 center, same surgeons?

Dr Galbut. I do not believe there were major differences. The overall operative mortalities were low.

Dr Furnary. Were radial arteries used in your practice, and how did you account for those?

Dr Galbut. Yes. We used them for a short while. Our belief is that the radial artery is not as advantageous as the in situ right internal thoracic artery (RITA) graft, and therefore it is easier to construct as an anastomosis, but our group has not used them in any large number.

Dr Furnary. In severely ischemic patients in whom we operate with coronary bypass, that often improves EF, and it seems to me that study categorization by preoperative EF assumes that the $\mathrm{EF}$ does not change, that is, operate on someone with a $30 \% \mathrm{EF}$ and postoperatively it goes to $50 \%$ or $55 \%$, and they are now in the category for survival of the $50 \% \mathrm{EF}$. Would it be possible to use postoperative $\mathrm{EF}$ rather than preoperative $\mathrm{EF}$ for categorization?

Dr Galbut. It would be great. That is another limitation of the study, and we accept that. 
Dr Furnary. In that light, have you considered doing just a single Cox regression instead of one for each group, a single Cox regression that would take into account $\mathrm{EF}$ as a variable?

Dr Galbut. Late EF?

Dr Furnary. No, even preoperative because we cannot get EF postoperatively or we do not have it in every patient.

Dr Galbut. Specific EF or the group?

Dr Furnary. One single Cox regression for the entire cohort of patients, groups I, II, and III, using EF as one of the variables.

Dr Galbut. One of our limitations, because the study goes back to a group that ended in 1994, is that the data registry has EF only in 3 categories, so it would be hard to say patient 2000 had an EF of $34 \%$, and that is discussed in the article as a major limitation.

Dr Furnary. Final question. Deep sternal wound infection. I noticed that your group uses skeletonized thoracic arteries, which is great, and there was no effect on deep sternal wound infection between bilateral and single. But there are other covariates or cofactors that also impart an increased risk, and usually bilateral thoracic artery grafting with some of those cofactors, such as diabetes, COPD, immune deficiency, obesity, is what has been shown in the literature to significantly increase deep sternal wound infection. Did you do any subanalyses?
Dr Galbut. In a prior article presented this year to the American Heart Association, we looked at diabetes, and within this group there was no increased incidence.

Dr Furnary. Great. Richard?

Dr Richard Shemin (Los Angeles, Calif). An incredible study. I cannot wait to see the whole article. I assume that the left internal thoracic artery (LITA) primarily always went to the left anterior descending (LAD). What was the strategy for the RITA?

Dr Galbut. Excellent question. The LITA went to the LAD. For a short while, we were using the RITA to the LAD and the LITA sequentially to circumflex branches. I never believed in that because in $90 \%$ of patients, the LITA is the most important and dominant vessel. LITA to the LAD will confer longevity, so that should not be risked. We wrote an article a couple years ago with Dr Kurlansky, who looked at where we placed the RITA, and what was noted is that it did not matter where the RITA was placed, whether it was to a proximal circumflex like a ramus or an important diagonal or the right coronary. I started taking the skeletonized RITA through the transverse sinus to gain length and anastomose it to a circumflex obtuse marginal branch one in the 1980s. To answer your question, my strategy, and I think the majority in the article, was to use the LITA to the LAD and the RITA to whichever artery was the best fit. 
APPENDIX E1. Preoperative variables and risk factors in unmatched ejection fraction groups

\begin{tabular}{|c|c|c|c|c|c|c|c|c|c|}
\hline \multirow[b]{2}{*}{ Variable } & \multicolumn{3}{|c|}{$\begin{array}{c}\text { Group I } \\
\text { unmatched patients } \\
\text { EF }<\mathbf{0 . 3 0}\end{array}$} & \multicolumn{3}{|c|}{$\begin{array}{c}\text { Group II } \\
\text { unmatched patients } \\
\text { EF } 0.30-0.50\end{array}$} & \multicolumn{3}{|c|}{$\begin{array}{c}\text { Group III } \\
\text { unmatched patients } \\
\text { EF }>\mathbf{0 . 5 0}\end{array}$} \\
\hline & SITA & BITA & $P$ value & SITA & BITA & $P$ value & SITA & BITA & $P$ value \\
\hline No. of patients & $146(100.0)$ & $87(100.0)$ & & $656(100.0)$ & $600(100.0)$ & & $1538(100.0)$ & $1510(100.0)$ & \\
\hline Gender & & & .242 & & & $<.001$ & & & .001 \\
\hline Male & $119(81.5)$ & $76(87.4)$ & & $525(80.0)$ & $535(89.2)$ & & 1,094 (71.1) & $1,258(83.3)$ & \\
\hline Female & $27(18.5)$ & $11(12.6)$ & & $131(20.0)$ & $65(10.8)$ & & $444(28.9)$ & $252(16.7)$ & \\
\hline \multicolumn{10}{|l|}{ Age at operation } \\
\hline Mean $\pm \mathrm{SD}$ & $66.9 \pm 9.7$ & $63.2 \pm 9.4$ & .004 & $68.0 \pm 8.8$ & $62.4 \pm 10.5$ & $<.001$ & $67.3 \pm 9.6$ & $63.1 \pm 9.8$ & $<.001$ \\
\hline \multicolumn{10}{|l|}{ Coronary risk factors } \\
\hline Family history of CAD & $72(49.3)$ & $45(51.7)$ & .722 & $321(48.9)$ & $313(52.2)$ & .252 & $790(51.4)$ & $834(55.2)$ & .032 \\
\hline Hypertension & $60(41.1)$ & $16(18.4)$ & $<.001$ & $236(36.0)$ & $204(34.0)$ & .464 & $568(36.9)$ & $586(38.8)$ & .285 \\
\hline Dyslipidemia & $20(13.7)$ & $8(9.2)$ & .307 & $99(15.1)$ & $99(16.5)$ & .494 & $227(14.8)$ & $236(15.6)$ & .504 \\
\hline Smoking history & $95(65.1)$ & $62(71.3)$ & .329 & $384(58.5)$ & $394(65.7)$ & .009 & $867(56.4)$ & 917 (60.7) & .015 \\
\hline Diabetes mellitus & $50(34.2)$ & $23(26.4)$ & .214 & $198(30.2)$ & $140(23.3)$ & .006 & $391(25.4)$ & $294(19.5)$ & $<.001$ \\
\hline \multicolumn{10}{|l|}{ Preoperative risk factors } \\
\hline Renal dysfunction & $6(4.1)$ & $5(5.7)$ & .569 & $39(5.9)$ & $21(3.5)$ & .042 & $60(3.9)$ & $38(2.5)$ & .030 \\
\hline Cerebrovascular disease & $10(6.8)$ & $7(8.0)$ & .734 & $43(6.6)$ & $17(2.8)$ & .002 & $88(5.7)$ & $51(3.4)$ & .002 \\
\hline Peripheral artery disease & $13(8.9)$ & $8(9.2)$ & .940 & $48(7.3)$ & $27(4.5)$ & .035 & $75(4.9)$ & $58(3.8)$ & .162 \\
\hline Prior myocardial infarction & $117(80.1)$ & $69(79.3)$ & .879 & $493(75.2)$ & $435(72.5)$ & .285 & $742(48.2)$ & $660(43.7)$ & .012 \\
\hline History of CHF & $52(35.6)$ & $24(27.6)$ & .206 & $150(22.9)$ & $71(11.8)$ & $<.001$ & $138(9.0)$ & $93(6.2)$ & .003 \\
\hline Unstable angina & $104(71.2)$ & $59(67.8)$ & .582 & $456(69.5)$ & $374(62.3)$ & .007 & $1,058(68.8)$ & $866(57.4)$ & $<.001$ \\
\hline \multicolumn{10}{|l|}{ Coronary angiography } \\
\hline 3-vessel disease & $131(89.7)$ & $80(92.0)$ & .574 & $564(86.0)$ & $526(87.7)$ & .377 & $1,236(80.4)$ & $1,229(81.4)$ & .471 \\
\hline
\end{tabular}

$E F$, Ejection fraction; SITA, single internal thoracic artery; $B I T A$, bilateral internal thoracic artery; $C H F$, chronic heart failure; $C A D$, coronary artery disease; $S D$, standard deviation.

APPENDIX E2. Comparison of operative data for propensity-matched ejection fraction groups

\begin{tabular}{|c|c|c|c|c|c|c|c|c|c|}
\hline \multirow[b]{2}{*}{ Variable } & \multicolumn{3}{|c|}{$\begin{array}{c}\text { Group I } \\
\text { matched patients } \\
\mathbf{E F}<\mathbf{0 . 3 0} \\
\end{array}$} & \multicolumn{3}{|c|}{$\begin{array}{c}\text { Group II } \\
\text { matched patients } \\
\text { EF 0.30-0.50 } \\
\end{array}$} & \multicolumn{3}{|c|}{$\begin{array}{c}\text { Group III } \\
\text { matched patients } \\
\mathbf{E F}>\mathbf{0 . 5 0} \\
\end{array}$} \\
\hline & SITA & BITA & $P$ value & SITA & BITA & $P$ value & SITA & BITA & $P$ value \\
\hline No. of patients & $87(100.0)$ & $87(100.0)$ & & $448(100.0)$ & $448(100.0)$ & & $1137(100.0)$ & $1137(100.0)$ & \\
\hline \multicolumn{10}{|l|}{ Total grafts } \\
\hline Distal grafts & & & .031 & & & .972 & & & .999 \\
\hline Mean \pm SD & $3.2 \pm 0.9$ & $3.5 \pm 0.9$ & & $3.2 \pm 0.9$ & $3.3 \pm 0.9$ & & $3.2 \pm 0.9$ & $3.3 \pm 0.9$ & \\
\hline Range & $2-6$ & $2-5$ & & $2-6$ & $2-6$ & & $2-6$ & $2-6$ & \\
\hline \multicolumn{10}{|l|}{ Cardiopulmonary bypass time } \\
\hline Perfusion time (min) & & & .663 & & & .305 & & & .325 \\
\hline Mean \pm SD & $130.4 \pm 41.3$ & $133.6 \pm 54.1$ & & $126.0 \pm 49.6$ & $122.7 \pm 47.9$ & & $115.1 \pm 43.9$ & $113.3 \pm 43.2$ & \\
\hline Range & $55-245$ & $55-391$ & & $15-386$ & $25-444$ & & $29-504$ & $31-422$ & \\
\hline Aortic crossclamp time (min) & & & .009 & & & $<.001$ & & & $<.001$ \\
\hline Mean $\pm \mathrm{SD}$ & $71.1 \pm 25.2$ & $80.9 \pm 23.4$ & & $70.5 \pm 24.9$ & $76.4 \pm 24.4$ & & $65.5 \pm 22.3$ & $71.7 \pm 23.0$ & \\
\hline Range & $13-185$ & $37-158$ & & $10-176$ & $12-200$ & & $10-237$ & $16-200$ & \\
\hline
\end{tabular}

$E F$, Ejection fraction; SITA, single internal thoracic artery; BITA, bilateral internal thoracic artery; $S D$, standard deviation. 


\section{APPENDIX E3. Definition of Terms}

Preoperative variables: Hypertension was defined as blood pressure ( $\geq 140$ systolic or $\geq 90$ diastolic) on 2 occasions or currently on antihypertensive medication. Hypercholestere$m i a$ was defined as a cholesterol of $>200 \mathrm{mg} / \mathrm{dL}$ on admission to the hospital. Renal insufficiency was defined as a documented history of renal failure with a creatinine of $\geq 2.0 \mathrm{mg} / \mathrm{dL}$ or on dialysis.

Surgical urgency: Elective surgery was defined as an operation, which could be deferred without increased risk of compromised cardiac outcome. Urgent surgery was defined as being required within 48 hours in an effort to prevent further clinical deterioration. Emergency surgery was defined as those instances when the patient had intractable angina or heart failure that did not respond to aggressive clinical measures or had impending infarction, or when decompensation occurred in the cardiac catheterization laboratory and measures such as defibrillation, extended cardiac massage, balloon counterpulsation, or inotropic support were required.

Postoperative variables: Respiratory insufficiency was defined as patients requiring ventilatory support for $>48$ hours or tracheostomy (or both). CVA was defined as a neurologic deficit that remained unresolved and presented for $>$ 24 hours. Perioperative $M I$ was defined as a new onset of $\mathrm{Q}$ waves with or without elevation of myocardial enzyme or a substantial elevation of myocardial enzymes alone. Renal insufficiency was defined as a documented history of renal failure with a creatinine of $\geq 2.0 \mathrm{mg} / \mathrm{dL}$ or on dialysis. Low cardiac output syndrome was defined as clinical evidence of hypotension, oliguria, and peripheral vascular constriction with normal or supranormal left ventricular filling pressure or a measured cardiac index of $<2 \mathrm{~L} / \mathrm{min}^{-1} / \mathrm{m}^{-2}$, necessitating the administration of catecholamines, use of intra-aortic balloon pump, or both. Deep sternal infection was defined as instability of the sternum with positive wound cultures necessitating an additional surgical procedure, such as incision and drainage, debridement, or secondary closure. Hospital mortality was defined as death occurring during the operation or the hospitalization in which the procedure was performed or death occurring after discharge from the hospital but within 30 days of the surgical procedure, unless the cause was clearly unrelated to the operation.

\section{APPENDIX E4. Covariates Used to Generate Propensity Scores}

Preoperative variables

1. Age at operation

2. Cerebrovascular disease

3. Diabetes mellitus

4. Diseased vessels
5. Dyslipidemia
6. Family history of coronary artery disease
7. Gender
8. Congestive heart failure
9. Hypertension
10. Peripheral artery disease
11. Prior myocardial infarction
12. Renal dysfunction
13. Smoking history
14. Unstable angina

\section{APPENDIX E5. Covariates Used to Predict In-Hospital Mortality}

Preoperative variables

1. Age at operation

2. Cerebrovascular disease

3. Diabetes mellitus

4. Family history of coronary artery disease

5. Gender

6. Congestive heart failure

7. Intra-aortic balloon pump inserted preoperatively

8. Left main disease

9. Peripheral artery disease

10. Prior myocardial infarction

11. Renal dysfunction

12. Smoking history

13. Surgical urgency

14. Unstable angina

Intraoperative variables

15. Aortic crossclamp time

16. Distal grafts

17. Group (SITA vs BITA)

\section{APPENDIX E6. Covariates Used to Predict Late Mortality}

Preoperative

1. Age at operation

2. Cerebrovascular disease

3. Congestive heart failure

4. Diabetes

5. Dyslipidemia

6. Family history of coronary artery disease

7. Gender

8. Hypertension

9. Intra-aortic balloon pump inserted preoperatively

10. Left main disease

11. Peripheral arterial disease

12. Prior myocardial infarction

13. Renal disease 
14. Smoking history

15. Surgical history

16. Surgical urgency

17. 3-vessel disease

18. Unstable angina

Intraoperative

19. Aortic crossclamp time

20. Distal grafts

21. Perfusion time
Postoperative

22. Cardiac arrest

23. Cerebrovascular accident

24. Deep sternal wound infection

25. Gastrointestinal disorder

26. Low cardiac output

27. Postoperative myocardial infarction

28. Pulmonary insufficiency

29. Renal dysfunction

30. Reoperation for bleeding

APPENDIX E7. Multivariate analysis of demographic and preoperative clinical variables associated with hospital mortality in unmatched ejection fraction groups

\begin{tabular}{|c|c|c|c|c|c|c|}
\hline Group/predictor & $\beta$ estimate & SE & Chi-square & $P$ value* & OR & $95 \% \mathbf{C I}$ \\
\hline \multicolumn{7}{|l|}{ Group I, EF $<0.30$} \\
\hline Age at operation & 0.061 & 0.0268 & 6.14 & .013 & 1.1 & $1.0-1.1$ \\
\hline Intra-aortic balloon pump inserted preoperatively & 1.304 & 0.4812 & 8.06 & .005 & 3.7 & $1.4-9.5$ \\
\hline \multicolumn{7}{|l|}{ Group II, EF 0.30-0.50 } \\
\hline Age at operation & 0.048 & 0.0167 & 9.44 & .002 & 1.0 & $1.0-1.1$ \\
\hline Congestive heart failure & 0.755 & 0.2969 & 6.09 & .014 & 2.1 & $1.2-3.8$ \\
\hline Intra-aortic balloon pump inserted preoperatively & 1.609 & 0.2868 & 31.00 & $<.001$ & 5.0 & $2.8-8.8$ \\
\hline Aortic crossclamp time (min) & 0.013 & 0.0050 & 6.24 & .012 & 1.0 & $1.0-1.0$ \\
\hline \multicolumn{7}{|l|}{ Group III, EF $>0.50$} \\
\hline Age at operation & 0.049 & 0.0139 & 13.68 & $<.001$ & 1.1 & $1.0-1.1$ \\
\hline Intra-aortic balloon pump inserted preoperatively & 1.716 & 0.2482 & 42.15 & $<.001$ & 5.6 & $3.4-9.0$ \\
\hline Aortic crossclamp time (min) & 0.018 & 0.0040 & 18.92 & $<.001$ & 1.0 & $1.0-1.0$ \\
\hline
\end{tabular}

$O R$, Odds ratio; $S E$, standard error; $C I$, confidence interval; $E F$, ejection fraction. *Only significant variables $(P<.050)$ are listed. 


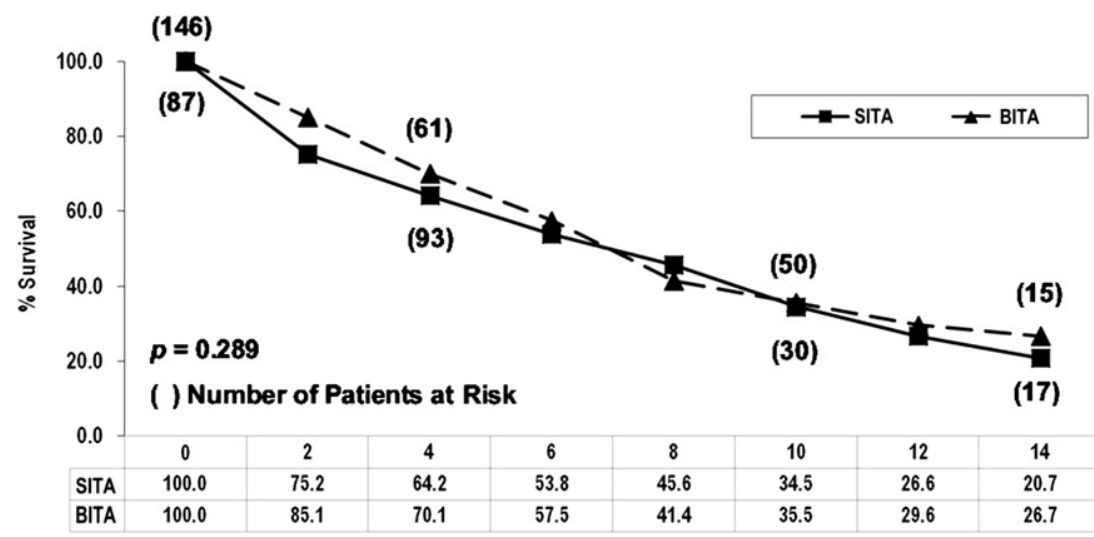

A

Years After Operation

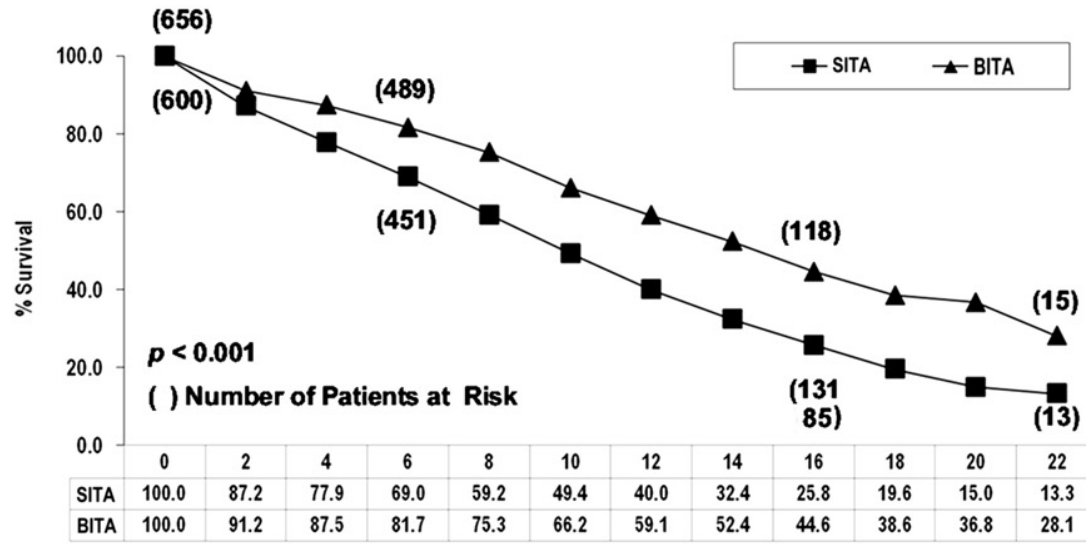

B

Years After Operation

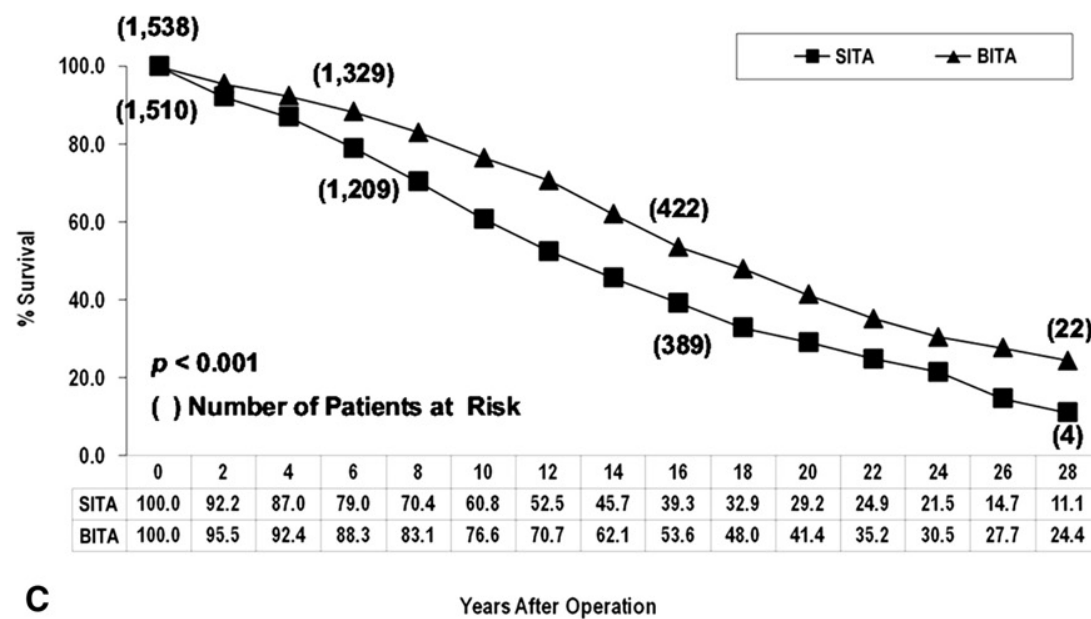

APPENDIX E8. A, Unmatched group I SITA and BITA recipients (EF < 0.30). B, Unmatched group II SITA and BITA recipients (EF 0.30-0.50). C, Unmatched group III SITA and BITA recipients $(\mathrm{EF}>0.50)$. 